\title{
Comparison of impedance measured by the forced oscillation technique and pulmonary functions, including static lung compliance, in obstructive and interstitial lung disease
}

This article was published in the following Dove Press journal:

International Journal of Chronic Obstructive Pulmonary Disease

\author{
Naoya Takeichi ${ }^{1}$ \\ Haruna Yamazaki' \\ Keisaku Fujimoto ${ }^{2}$ \\ 'Department of Biomedical Laboratory \\ Sciences, Graduate School of Medicine, \\ Shinshu University, Matsumoto, Nagano, \\ Japan; ${ }^{2}$ Department of Clinical \\ Laboratory Sciences, Shinshu University \\ School of Health Sciences, Matsumoto, \\ Nagano, Japan
}

Objective: To examine whether the parameters of impedance measured by the broadband frequency forced oscillation technique (FOT) were reflected by changes in lung compliance induced by emphysema and fibrosis, we retrospectively compared the parameters of FOT and pulmonary functions, including static lung compliance (Cst), in obstructive lung disease (OLD) and interstitial lung disease (ILD).

Patients and methods: The data of 18 patients with OLD (16 with COPD, two with asthma COPD overlap), 11 with ILD, and 24 healthy volunteers, whose respiratory impedance was measured using a MostGraph-01 and other pulmonary functions including Cst and lung resistance $\left(\mathrm{R}_{\mathrm{L}}\right)$ were measured on the same day and were retrospectively collected and compared.

Results: The parameters of resistance, reactance, and resonant frequency showed good correlations with ventilation unevenness $(r=0.63,-0.89,0.77$, respectively) and lung elastic resistance $(r=0.59,-0.80,0.73$, respectively) in all groups $(\mathrm{N}=53)$. These indices were significant determinants of increased respiratory resistance and more negative shift of respiratory reactance $(\mathrm{Xrs})$ at lower frequency $(P<0.001)$. Decreased functional residual capacity was also a determinant of Xrs at $5 \mathrm{~Hz}(\mathrm{X} 5)(P<0.05)$. The differences in mean $\mathrm{X} 5$ in the expiratory phase relative to those in the inspiratory phase (within-breath changes in X5) were associated with airflow obstruction $(P<0.002)$ and lung elastic resistance $(P<0.001)$. However, no significant correlations between Cst and any parameters of respiratory impedance were observed.

Conclusions: These findings suggest that the impedance parameters measured by FOT are reflected by airway obstruction, ventilation unevenness, and lung resistance, but hardly reflected by changes in lung compliance due to emphysema or fibrosis in both CLD and ILD.

Keywords: forced oscillation technique, resistance, reactance, esophageal balloon method, chronic obstructive pulmonary disease

\section{Introduction}

Respiratory impedance determined using the broadband frequency forced oscillation technique (FOT) can be evaluated by separating respiratory reactance (Xrs) from respiratory resistance (Rrs). Rrs represents the sum of airway resistance and viscous resistance of lung and thoracic tissue ${ }^{1}$, while Xrs is considered to reflect the dynamic
Department of Clinical Laboratory Sciences, Shinshu University School of Health Sciences, 3-I-I Asahi, Matsumoto, Nagano 390-862I, Japan

Tel +8 I263372393

Fax +8 I263372393

Email keisaku@shinshu-u.ac.jp 
elastance and inertia of the respiratory system. ${ }^{2}$ The parameters of respiratory impedance can also be evaluated by the pattern of Rrs and Xrs dependent on the frequency of oscillation and by the differences between the mean Rrs and Xrs in the expiratory phase and those in the inspiratory phase (within-breath). ${ }^{3}$ The respiratory impedance can be easily measured by the FOT method even in young children and the elderly due to the minimal effort of resting breathing within 1 minute. ${ }^{4}$ FOT has been reported to show complementary usefulness for pathophysiological assessment, management, and assessment of treatment effectiveness in the obstructive lung diseases, asthma and COPD. ${ }^{3}$ Patients with obstructive lung disease (OLD) show increased Rrs and more negative shift of Xrs value at lower frequency, and increased resonant frequency ( $f$ res) depending on the severity of airflow obstruction. ${ }^{5-7}$ In addition, it has been reported that within-breath changes are increased in Xrs in patients with severe COPD, which may be associated with expiratory airflow limitation (EFL) due to airway narrowing and decreased lung elastic recoil pressure. ${ }^{6-8}$ Alternatively, increased Rrs and more negative shift of Xrs at lower frequency as well as increased $f$ res were also demonstrated in cases of interstitial lung disease (ILD) as in COPD., ${ }^{9,10}$ It should also be noted that lung compliance is decreased in ILD, while compliance is increased in emphysema. However, the changes in resistance and reactance at lower frequency in these two disease conditions are qualitatively similar. Wada et $\mathrm{al}^{11}$ reported that there were no significant correlations between FOT parameters and the degree of emphysema on high-resolution computed tomography (HRCT). Thus, it has been suggested that the increased Rrs and more negative shift of Xrs at lower frequency may be not a measure of lung compliance. These changes in the resistance and reactance have been suggested to be due to the presence of peripheral airway inflammation in OLD and ILD or to be associated with increased elastic recoil pressure and decreased lung volume due to pulmonary fibrosis. ${ }^{10}$ However, most of these interpretations were not based on direct measurement of the lung structure and lung compliance, but were derived from physical models or circumstantial evidence involving comparison of respiratory impedance with other conventional physiological tests. ${ }^{12}$ In OLD and ILD, it is not yet clear whether the changes in Rrs and Xrs at lower frequency may reflect peripheral airway narrowing and stiffness due to airway inflammation or may also be related to changes in lung elastic recoil pressure due to pulmonary emphysema or fibrosis.

In the present study, the associations between the parameters of FOT and static lung compliance (Cst) and lung resistance $\left(\mathrm{R}_{\mathrm{L}}\right)$ in addition to other pulmonary function tests were retrospectively evaluated in OLD and ILD to clarify the contributions of pathological changes in lung parenchyma, such as those occurring in emphysema or fibrosis.

\section{Materials and methods}

Subjects who underwent measurement of lung compliance and lung resistance using an esophageal balloon, respiratory impedance by the FOT method using a MostGraph-01 (Chest Co., Ltd, Tokyo, Japan), spirometry, lung volume of functional residual capacity (FRC), lung diffusion capacity of carbon monoxide (DLCO), and $\mathrm{N}_{2}$ phase III slope of single-breath $\mathrm{N}_{2}$ washout $\left(\Delta \mathrm{N}_{2}\right)$ at Shinshu University Hospital between April 2013 and March 2017 were retrospectively recruited. We collected data from subjects over 20 years old who had all measurements performed on the same day, and excluded subjects whose diagnosis was undetermined and those whose measurements could not be performed properly. We examined the relationships between parameters of respiratory impedance and other pulmonary function tests, including Cst and $\mathrm{R}_{\mathrm{L}}$. All subjects were given an adequate explanation of the study and provided written informed consent. This study was conducted in accordance with the International Conference on Harmonization-Good Clinical Practice, and the Declaration of Helsinki (2008), and approval by the institutional research ethics committee of Shinshu University Hospital (approval number: 3753).

\section{Measurement of respiratory impedance by the FOT method}

Respiratory impedance was measured using a commercially available FOT device (MostGraph-01; Chest Co., Ltd). ${ }^{2,4}$ Respiratory impedance measurements were performed during tidal breath for 60 seconds in the sitting position, supporting the subject's cheeks and mouth floor to reduce upper airway shunting. We evaluated Rrs at $5 \mathrm{~Hz}$ (R5), Rrs at 20 $\mathrm{Hz}$ (R20), the difference from R5 to R20 (R5-R20), Xrs at 5 $\mathrm{Hz}$ (X5), resonant frequency (fres), and also the differences of the mean Rrs and Xrs in the expiratory phase to those in the inspiratory phase (expressed as within-breath or delta). Whole-breath analysis and within-breath analysis were performed automatically by the software. These FOT measurements were performed at least three times prior to other pulmonary function tests. 


\section{Lung compliance}

Both static lung compliance and dynamic lung compliance were measured by the esophageal balloon method using a body box (Chestac8900; Chest Co., Ltd). Prior to the test, the nasal cavity was anesthetized with xylocaine spray, and the esophageal balloon catheter (Chest Co., Ltd) was passed through the nose, and secured $10 \mathrm{~cm}$ above the esophagogastric junction while monitoring the pressure of the esophageal balloon. First, after maximum inspiration, the subjects were asked to exhale from maximum inspiratory level to maximum expiratory level in increments of $300-500 \mathrm{~mL}$. We drew a lung pressure-volume $(\mathrm{P}-\mathrm{V})$ curve using transpulmonary pressure (Ptp) (the difference between oral and esophageal pressures) and lung volume. The regression analysis was performed using a sigmoidal equation of the form, $\mathrm{V}=a+b\left[1+\mathrm{e}^{-(P-c) / d}\right]^{-1}$, for its ability to characterize lung and respiratory system $\mathrm{P}-\mathrm{V}$ curves obtained under a variety of conditions including normal and OLD and ILD lungs. ${ }^{13}$ In this equation, $a$ corresponds to the volume of a lower asymptote, $b$ to the volume difference between upper and lower asymptotes, $c$ to the pressure at the inflection point of the sigmoidal curve, and $d$ to the proportional to the pressure range within which most of the volume change takes place. The Cst was calculated as the slope between resting expiratory level (FRC level) and 500-mL inspiratory level (Figure 1), and the Ptp at the point of maximum inspiration (Pes max) was also measured. Subsequently, we measured dynamic lung compliance (Cdyn) and $\mathrm{R}_{\mathrm{L}}$ at

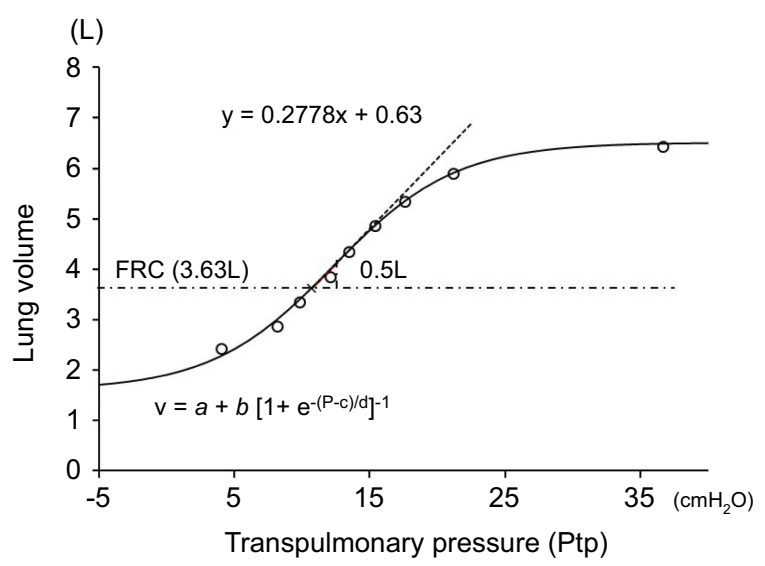

Figure I Sigmoidal regression analysis fitted to the data and calculation of static lung compliance in one healthy subject.

Notes: The regression analysis was performed using a sigmoidal equation of the form, $\mathrm{V}=a+b\left[1+\mathrm{e}^{-(P-c) / d}\right]^{-1}, a$ corresponds to the volume of a lower asymptote, $b$ to the volume difference between upper and lower asymptotes, $c$ to the pressure at the inflection point of the sigmoidal curve, and $d$ to the proportional to the pressure range within which most of the volume change takes place. The static lung compliance (Cst) was calculated as the slope between resting expiratory level (FRC level) and 500-mL inspiratory level.

Abbreviations: FRC, functional residual capacity; Ptp, transpulmonary pressure; Cst, static lung compliance. a resting respiratory rate of $0.25 \mathrm{~Hz}$, and the last five breaths were analyzed breath-by-breath. Cdyn was obtained from the following the equation: Cdyn $=V_{T} /(E I-P t p ~-~ E E-P t p)$, and $R_{L}$ was determined by multivariate regression using a simple linear equation of motion, ${ }^{14,15}$ as follows: $\Delta \mathrm{Ptp}=\mathrm{R}_{\mathrm{L}} \cdot \mathrm{V}+\mathrm{V} /$ Cdyn. $V_{T}$ corresponds tidal volume, EI-Ptp to end inspiratory Ptp, and EE-Ptp to end expiratory Ptp. Cdyn and RL at a resting respiratory rate of $0.25 \mathrm{~Hz}$, and then the respiratory rate was incrementally increased to $0.7 \mathrm{~Hz}, 0.9 \mathrm{~Hz}$, and $1.2 \mathrm{~Hz}$ using a metronome. We performed linear regression for Cdyn, and then determined Cdyn for $1 \mathrm{~Hz}(\mathrm{C} 1)$, and calculated the $\mathrm{C} 1 / \mathrm{Cst}$ parameter as an index of the frequency dependence of Cdyn. If the air trapping is present, end-expiratory lung volume is increased in accordance with the increase of respiratory frequency, which is called dynamic lung hyperinflation (DLH), which results in the shift of $\mathrm{P}-\mathrm{V}$ loop of tidal breathing to right upper direction on the $\mathrm{P}-\mathrm{V}$ curve, and Cdyn is decreased. Therefore, the $\mathrm{C} 1 / \mathrm{Cst}$ represents easy to develop DLH by air trapping.

\section{Pulmonary function test}

Spirometry, lung volume of FRC determined by body plethysmography, DLCO determined by the single-breath method, and the $\mathrm{N}_{2}$ phase III slope of single-breath $\mathrm{N}_{2}$ washout $\left(\Delta \mathrm{N}_{2}\right)$, a marker of ventilation unevenness, were measured using a Chestac-8900 (Chest Co., Ltd). For the predicted values of forced expiratory volume in 1 second $\left(\mathrm{FEV}_{1}\right)$ and vital capacity (VC), Japanese local reference data ${ }^{17}$ developed by the Japanese Respiratory Society were adopted, and the predicted values for DLCO and lung volumes (FRC, RV, and TLC) measured by body plethysmography were determined using the formulas of Nishida et $\mathrm{al}^{18}$ and Boren et $\mathrm{al}^{19}$ respectively.

\section{Statistical analysis}

Values in the text, tables, and figures are shown as the means \pm SEM. The Mann-Whitney $U$ test was used for comparison of various parameters among groups. Spearman's rank correlation coefficient was used for bivariate correlation analysis of the parameters of respiratory impedance and pulmonary function tests. Multiple stepwise linear regression analysis was performed to determine which variables were significant determinants of R5-R20, X5, and $\Delta \mathrm{X} 5$. These statistical analyses were performed using SPSS Version 22 (IBM Corporation, Armonk, NY, USA). In all analyses, $P<0.05$ was taken to indicate statistical significance. 


\section{Results}

The data of 52 subjects, consisting of 23 healthy subjects (HS), 18 patients with chronic OLD (16 with COPD and two with asthma COPD overlap [ACO]), and 11 patients with ILD (7 with idiopathic pulmonary fibrosis (IPF) and 3 with pulmonary fibrosis due to collagen disease) were included in the analysis. Seven patients with ILD had smoking history and 2 had emphysema on HRCT. Ten subjects were excluded from the analysis for a number of reasons as follows: 4 subjects due to lack of complete data, 1 healthy subject due to poor testing, and 5 subjects due to lack of definitive diagnosis. The characteristics and pulmonary function data, except the data of respiratory impedance, for the three groups, ie HS, OLD, and ILD, are shown in Table 1. Concerning with pulmonary function testing, lung hyperinflation, decreased diffusing capacity, and ventilation unevenness in addition to airflow obstruction in OLD, and decreased lung volume, decreased diffusing capacity, and ventilation unevenness in ILD were observed. Both the Cst and Cdyn were decreased in ILD, but there were no significant differences between OLD and HS. Alternatively, the $\mathrm{R}_{\mathrm{L}}$ was significantly increased in both OLD and ILD. Concerning with the frequencydependent decrease in Cdyn, the Cdyn was rapidly decreased from Cst in accordance with the increases of respiratory frequency in OLD. However, in patients with ILD, the Cdyn was decreased from Cst, with almost no change even though the respiratory frequency was increased (Figure 2).

The results of the respiratory impedance parameters are shown in Table 2. In the OLD group, R5-R20 and fres were increased and X5 showed more negative values. In addition, the within-breath changes in X5 ( $\triangle X 5)$ were greater than those in the HS group. The ILD group showed significant increases in R5, R5-R20, fres, and greater within-breath changes in R5-R20 and significantly more negative values of X5. The within-breath changes in X5 were greater than those in the HS group, but smaller compared to those in OLD. Among all subjects, better correlation coefficients were obtained on simple linear regression analysis as shown in Table 3. In the OLD group, R5-R20 showed significant correlations with airflow obstruction, $\Delta \mathrm{N}_{2}$ and $\mathrm{R}_{\mathrm{L}}$ (Table 4). X5 and fres showed significant correlations with the same parameters as in the case of R5-R20. $\triangle X 5$ showed significant correlations with $\mathrm{VC}, \mathrm{R}_{\mathrm{L}}$, and airflow obstruction, and a tendency to correlate with the respiratory frequency dependent decrease of Cdyn (C1/Cst). However, Cst did not show any significant correlations with pulmonary function parameters, but $\mathrm{R}_{\mathrm{L}}$ showed significant correlations with $\mathrm{R} 5-$ R20 and X5 (Figure 3). In the ILD group, R5, R5-R20, $\mathrm{X} 5$, and fres showed strong correlations with $\Delta \mathrm{N}_{2}$, and both $\mathrm{X} 5$ and fres showed strong correlations with $\mathrm{VC}$, $\mathrm{FEV}_{1}$, and $\mathrm{R}_{\mathrm{L}}$, but no correlations with Cst were observed (Table 5) (Figure 4). Multiple stepwise regression analysis among all subjects indicated that the regression model for R5-R20 was significant $(r=0.73, P<0.001)$ and consisted of age $(\operatorname{std} \beta=0.32, P<0.001), \mathrm{R}_{\mathrm{L}}(\operatorname{std} \beta=0.32, P<0.001)$ and $\Delta \mathrm{N}_{2}(\operatorname{std} \beta=0.32, P<0.001)$; that for $\mathrm{X} 5$ was significant $(r=0.92, P<0.001)$ and consisted of $\Delta \mathrm{N}_{2}(\operatorname{std} \beta=-$ $0.64, P<0.001), \mathrm{R}_{\mathrm{L}}(\operatorname{std} \beta=-0.31, P<0.001)$, and $\mathrm{FRC}$ $(\operatorname{std} \beta=0.12, P<0.05)$; and that for $\triangle \mathrm{X} 5$ was significant $(r=0.67, P<0.01)$ and consisted of $\mathrm{R}_{\mathrm{L}}(\operatorname{std} \beta=-0.50, P$ $<0.001), \mathrm{FEV}_{1} / \mathrm{FVC}(\operatorname{std} \beta=0.40, P<0.002)$, and VC $(\operatorname{std} \beta$ $=-0.33, P<0.05)$.

\section{Discussion}

We retrospectively examined the relationships between the parameters of respiratory impedance measured by FOT and the pulmonary function test data including Cst and $\mathrm{R}_{\mathrm{L}}$ in patients with OLD and ILD. The parameters of R5R20, X5, and fres showed good correlations with airflow obstruction, ventilation unevenness and lung elastic resistance, and these indices were significant determinants of increased Rrs and more negative shift of Xrs at low frequency, and decreased FRC was also a determinant of X5. $\triangle \mathrm{X} 5$ was associated with airflow obstruction and lung elastic resistance in expiration. However, no significant correlations between Cst and parameters of respiratory impedance were observed. These findings suggested that the low frequency-dependent increase in Rrs and more negative shift of Xrs mainly reflect the closed and collapsed peripheral airways and/or alveoli, which result in lung de-recruitment, but do not directly reflect lung parenchymal changes, such as emphysema and fibrosis, represented as changes in Cst.

In OLD, the increased Rrs and more negative shift of Xrs at low frequency were observed and showed significant associations with airflow obstruction, ventilation unevenness, and lung elastic resistance, but not with Cst. Usually, highfrequency waves reflect back from large airways and lowfrequency waves travel deep into the lungs. ${ }^{2}$ However, if flow limitation is present, oscillatory waves cannot pass through the closed and collapsed peripheral airways and 
Table I Characteristics and the results of pulmonary function test of healthy subjects and patients with obstructive lung disease and interstitial lung disease

\begin{tabular}{|c|c|c|c|}
\hline & HS & OLD & ILD \\
\hline Number & 23 & 18 & 11 \\
\hline Age, years & $61.5 \pm 2.9$ & $75.9 \pm 1.9 * *$ & $68.3 \pm 3.2$ \\
\hline Sex, male/female & $23 / 0$ & $18 / 0$ & $10 / 1$ \\
\hline Smoking history, pack $\cdot$ year & $12.6 \pm 3.7$ & $40.5 \pm 6.3 * *$ & $23.7 \pm 7.4$ \\
\hline BMI, $\mathrm{kg} / \mathrm{m}^{2}$ & $23.4 \pm 0.5$ & $21.0 \pm 0.5 * *$ & $22.3 \pm 2.2^{\dagger}$ \\
\hline VC, \% & $107.5 \pm 2.0$ & $110.0 \pm 2.4$ & $78.0 \pm 7.5 * *+\dagger$ \\
\hline $\mathrm{FEV}_{1}, \%$ & $106.7 \pm 2.3$ & $75.0 \pm 3.4 * *$ & $72.6 \pm 6.9 * *$ \\
\hline $\mathrm{FEV}_{1} / \mathrm{FVC}, \%$ & $81.3 \pm 1.4$ & $55.0 \pm 2.8 * *$ & $76.7 \pm 2.9$ t† \\
\hline FRC, \% & $102.1 \pm 2.9$ & $103.1 \pm 3.6$ & $80.0 \pm 5.1 * *+\dagger$ \\
\hline $\mathrm{RV}, \%$ & $126.8 \pm 5.1$ & $158.3 \pm 10.0 *$ & $108.6 \pm 5.7 * \dagger t$ \\
\hline TLC, \% & $120.3 \pm 3.5$ & $|3| .7 \pm 4.6$ & $87.9 \pm 5.5 * *+\dagger$ \\
\hline RV/TLC, \% & $34.2 \pm 1.4$ & $43.4 \pm 1.7 * *$ & $41.4 \pm 2.5 *$ \\
\hline DLCO, \% & $99.5 \pm 3.2$ & $65.4 \pm 6.2 * *$ & $53.8 \pm 4.9 * *$ \\
\hline $\mathrm{DLCO} / \mathrm{V}_{\mathrm{A}}, \%$ & $118.5 \pm 4.3$ & $76.1 \pm 7.0 * *$ & $93.1 \pm 7.3 * *$ \\
\hline$\Delta \mathrm{N}_{2}, \%$ & $1.03 \pm 0.11$ & $3.80 \pm 0.48 * *$ & $7.12 \pm 3.19 * *$ \\
\hline Cst, $\mathrm{L} / \mathrm{cmH}_{2} \mathrm{O}$ & $0.24 \pm 0.02$ & $0.27 \pm 0.03$ & $0.09 \pm 0.02 * *+\dagger$ \\
\hline Pes max, $\mathrm{cmH}_{2} \mathrm{O}$ & $-22.8 \pm 1.5$ & $-14.8 \pm 1.6 * *$ & $-24.2 \pm 5.1$ \\
\hline $\mathrm{Cdyn}, \mathrm{L} / \mathrm{cmH}_{2} \mathrm{O}$ & $0.14 \pm 0.01$ & $0.15 \pm 0.01$ & $0.07 \pm 0.01 * *+\dagger$ \\
\hline $\mathrm{R}_{\mathrm{L}}, \mathrm{cmH}_{2} \mathrm{O} / \mathrm{L} / \mathrm{s}$ & $1.92 \pm 0.16$ & $3.04 \pm 0.39 * *$ & $5.32 \pm 1.19 * *$ \\
\hline$\Delta \mathrm{R}_{\mathrm{L}}, \mathrm{cmH}_{2} / \mathrm{L} / \mathrm{s}$ & $1.29 \pm 0.29$ & $1.63 \pm 0.28$ & $3.94 \pm 1.15 * *$ \\
\hline $\mathrm{Cl} /$ Cst,\% & $61.0 \pm 12.3$ & $33.8 \pm 4.1 * *$ & $111.3 \pm 32.8^{t t}$ \\
\hline
\end{tabular}

Notes: Values are means \pm SEM. $* P<0.05$ and $* * P<0.01$ vs $\mathrm{HS},{ }^{\dagger}<0.05$ and ${ }^{\dagger \dagger}<0.01$ vs OLD.

Abbreviations: HS, healthy subjects; OLD, obstructive lung diseases; ILD, interstitial lung disease; BMI, body mass index; VC, vital capacity; FEV , forced expiratory volume in I second; FVC, forced vital capacity; FRC, functional residual capacity; RV, residual volume; TLC, total lung capacity; DLCO, lung diffusion capacity of carbon monoxide; $\triangle \mathrm{N}_{2}$, N2 phase III slope of single-breath N2 washout; Cst, static compliance; Pes max, maximum difference between esophageal and oral pressure at the level of total lung capacity; Cdyn, dynamic compliance; $R_{L}$, lung resistance; $\Delta R_{L}$, within-breath changes in $R_{L} ; C l$, Cdyn during respiratory rate at $\mathrm{I} \mathrm{Hz;} \mathrm{Cl} / \mathrm{Cst}$, an index of frequency dependency.

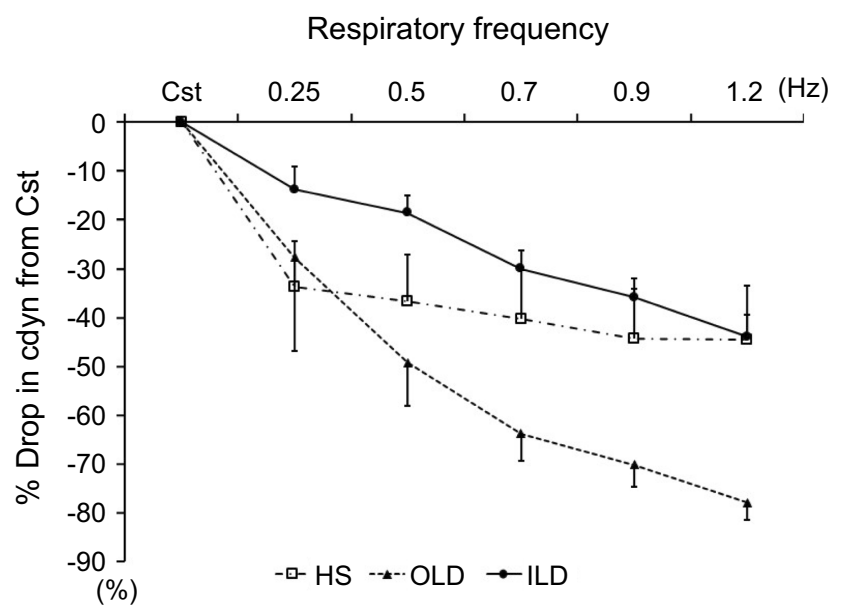

Figure 2 Percentage drop in Cdyn from Cst in accordance with the increased respiratory frequency in healthy subjects, patients with obstructive lung disease and interstitial lung disease.

Notes: In the HS group, the decreased of Cdyn was mild, but in OLD, the Cdyn was rapidly decreased from Cst. However, in patients with ILD, the Cdyn was decreased from Cst, withalmost no change even though the respiratory frequency was increased. Abbreviations: Cdyn, dynamic lung compliance; Cst, static lung compliance; HS, healthy subjects; OLD, obstructive lung disease; ILD, interstitial lung disease.

reach alveoli, thereby the oscillations are absorbed by the airway walls, which results in the decrease of lung compliance and further negative shift of reactance. ${ }^{8}$ The treatment with beta-2-bronchodilator, can dilate peripheral airways, has been demonstrated to increase Xrs at low frequency and fres by lung recruitment via the opening of closed airways. ${ }^{20}$ It has been suggested that the Xrs at low frequency is sensitive to severe airway narrowing, expiratory flow limitation, heterogeneity of airway caliber, and airway closure. ${ }^{21,22}$ It has been also demonstrated that the rapid onset of de-recruitment measured by Xrs is a surrogate marker of closing capacity, ${ }^{23}$ which corresponded to the good correlations between the more negative shift of X5 and ventilation unevenness in the present study. From the above evidence, the parameters of FOT hardly reflected the decreased lung elastic recoil pressure represented by Cst. Wada et al ${ }^{11}$ quantitatively evaluated both emphysematous and airway lesions in COPD patients by HRCT, and examined the relationships with indices of respiratory impedance. They reported that R5, R20, and X5 were correlated with airway wall thickening, but not with emphysematous lesions, and that the indices of FOT reflected the extent of airway lesions. Using three-dimensional HRCT, Karayama et $\mathrm{al}^{24}$ demonstrated that indices of respiratory resistance and 
Table 2 Results of respiratory impedance measured by the multifrequency forced oscillation technique in healthy subjects, patients with obstructive lung disease, and interstitial lung disease

\begin{tabular}{|c|c|c|c|}
\hline & HS & OLD & ILD \\
\hline Number & 23 & 18 & 11 \\
\hline $\mathrm{R} 5, \mathrm{cmH}_{2} \mathrm{O} / \mathrm{L} / \mathrm{s}$ & $1.72 \pm 0.18$ & $2.22 \pm 0.19$ & $3.08 \pm 0.5 I^{* *}$ \\
\hline $\mathrm{R} 20, \mathrm{cmH}_{2} \mathrm{O} / \mathrm{L} / \mathrm{s}$ & $1.50 \pm 0.14$ & $1.71 \pm 0.11$ & $2.22 \pm 0.29 *$ \\
\hline $\mathrm{R} 5-\mathrm{R} 20, \mathrm{cmH}_{2} \mathrm{O} / \mathrm{L} / \mathrm{s}$ & $0.22 \pm 0.07$ & $0.51 \pm 0.11 *$ & $0.86 \pm 0.24 * *$ \\
\hline $\mathrm{X} 5, \mathrm{cmH}_{2} \mathrm{O} / \mathrm{L} / \mathrm{s}$ & $-0.30 \pm 0.04$ & $-0.71 \pm 0.16 *$ & $-1.52 \pm 0.48^{* *}$ \\
\hline fres, $\mathrm{Hz}$ & $7.37 \pm 0.42$ & $10.37 \pm 1.00 * *$ & $14.17 \pm 1.89 * *$ \\
\hline$\Delta \mathrm{R} 5, \mathrm{cmH}_{2} \mathrm{O} / \mathrm{L} / \mathrm{s}$ & $0.27 \pm 0.06$ & $0.39 \pm 0.09$ & $0.6 I \pm 0.2 I$ \\
\hline$\Delta(\mathrm{R} 5-\mathrm{R} 20), \mathrm{cmH}_{2} \mathrm{O} / \mathrm{L} / \mathrm{s}$ & $0.14 \pm 0.03$ & $0.17 \pm 0.05$ & $0.45 \pm 0.12 * * \dagger$ \\
\hline$\Delta \mathrm{X} 5, \mathrm{cmH}_{2} \mathrm{O} / \mathrm{L} / \mathrm{s}$ & $0.06 \pm 0.03$ & $-0.31 \pm 0.14 * *$ & $-0.11 \pm 0.10^{*}$ \\
\hline
\end{tabular}

Notes: Values are means \pm SEM. $* P<0.05$ and $* * P<0.01$ vs HS, ${ }^{\dagger}<0.05$ vs OLD.

Abbreviations: $\mathrm{HS}$, healthy subjects; OLD, obstructive lung disease; ILD, interstitial lung disease; R5, respiratory resistance at $5 \mathrm{~Hz}$; R20, respiratory resistance at $20 \mathrm{~Hz}$; $\mathrm{R} 5-\mathrm{R} 20$, difference from $\mathrm{R} 20$ to $\mathrm{R} 5$; $\mathrm{X} 5$, respiratory reactance at $5 \mathrm{~Hz}$; fres, resonant frequency.

Table 3 Correlations between parameters of respiratory impedance and pulmonary function tests among healthy subjects and patients with obstructive lung disease and interstitial lung disease (total 53 subjects)

\begin{tabular}{|c|c|c|c|c|c|c|}
\hline & $\mathbf{R 5}$ & R5-R20 & $\times 5$ & fres & $\Delta \mathrm{R5}$ & $\Delta \times 5$ \\
\hline vc,\% & $-0.32 *$ & $-0.30 *$ & $0.5 I^{* *}$ & $-0.5 I^{* *}$ & -0.15 & -0.15 \\
\hline$\% \mathrm{FEV}_{1}, \%$ & $-0.50 * *$ & $-0.53 * *$ & $0.65 * *$ & $-0.75 * *$ & -0.17 & $0.40 * *$ \\
\hline $\mathrm{FEV}_{1} / \mathrm{FVC}, \%$ & -0.28 & $-0.33^{*}$ & 0.25 & $-0.40 * *$ & -0.08 & $0.56 * *$ \\
\hline DLCO, \% & $-0.37^{* *}$ & $-0.48^{* *}$ & $0.48 * *$ & $-0.61 * *$ & -0.19 & $0.33^{*}$ \\
\hline FRC, \% & $-0.3 I^{*}$ & $-0.30 *$ & $0.28^{*}$ & $-0.32 *$ & -0.22 & 0.03 \\
\hline$\Delta N_{2}, \%$ & $0.59 * *$ & $0.63 * *$ & $-0.89 * *$ & $0.77^{* *}$ & $0.34^{*}$ & $-0.33 *$ \\
\hline Cst, $\mathrm{L} / \mathrm{cmH}_{2} \mathrm{O}$ & -0.16 & -0.16 & 0.27 & $-0.31 *$ & 0.03 & -0.27 \\
\hline $\mathrm{Cl} / \mathrm{Cst}, \%$ & 0.18 & 0.11 & -0.03 & 0.09 & -0.02 & 0.20 \\
\hline $\mathrm{R}_{\mathrm{L}}, \mathrm{cmH}_{2} \mathrm{O} / \mathrm{L} / \mathrm{s}$ & $0.57^{* *}$ & $0.59 * *$ & $-0.80 * *$ & $0.73 * *$ & 0.22 & $-0.35^{*}$ \\
\hline
\end{tabular}

Notes: $* P<0.05$ and $* * P<0.01$

Abbreviations: $\mathrm{HS}$, healthy subjects; OLD, obstructive lung disease; ILD, interstitial lung disease; R5, respiratory resistance at $5 \mathrm{~Hz}$; R20, respiratory resistance at $20 \mathrm{~Hz}$; $\mathrm{R} 5$ - R20, difference from R20 to R5; X5, respiratory reactance at $5 \mathrm{~Hz}$; fres, resonant frequency; $\Delta R 5$ and $\Delta X 5$, within-breath changes in R5 and X5; VC, vital capacity; $\mathrm{FEV}_{1}$, forced expiratory volume in I second; FVC, forced vital capacity; DLCO, lung diffusion capacity of carbon monoxide; $\Delta \mathrm{N}_{2}$, N2 phase III slope of single-breath N2 washout; Cst, static compliance; $\mathrm{Cl}$, Cdyn during respiratory rate at I $\mathrm{Hz}$; $\mathrm{Cl} / \mathrm{Cst}$, an index of frequency dependency; $\mathrm{R}_{\mathrm{L}}$, lung resistance.

Table 4 Correlations between parameters of respiratory impedance and pulmonary function tests in 18 patients with obstructive lung disease

\begin{tabular}{|c|c|c|c|c|c|c|}
\hline & $\mathbf{R 5}$ & R5-R20 & $\times 5$ & fres & $\Delta R 5$ & $\Delta \times 5$ \\
\hline VC, \% & 0.33 & 0.43 & -0.42 & 0.29 & -0.03 & $-0.47^{*}$ \\
\hline$\% F E V_{1}, \%$ & -0.42 & $-0.55^{*}$ & $0.66 * *$ & $-0.80 * *$ & 0.13 & 0.40 \\
\hline $\mathrm{FEV}_{1} / \mathrm{FVC}, \%$ & -0.45 & $-0.61 * *$ & $0.75 * *$ & $-0.87^{* *}$ & 0.14 & $0.55^{*}$ \\
\hline DLCO, \% & -0.18 & -0.44 & 0.38 & $-0.62^{* *}$ & -0.12 & 0.31 \\
\hline FRC, \% & 0.15 & 0.18 & 0.06 & -0.24 & -0.04 & 0.09 \\
\hline$\Delta N_{2}, \%$ & 0.29 & $0.55^{*}$ & $-0.67^{* *}$ & $0.82 * *$ & -0.27 & -0.42 \\
\hline Cst, $\mathrm{L} / \mathrm{cmH}_{2} \mathrm{O}$ & 0.13 & 0.11 & -0.15 & -0.02 & 0.13 & -0.35 \\
\hline Cl/Cst, \% & -0.17 & -0.23 & 0.38 & -0.24 & 0.12 & 0.46 \\
\hline $\mathrm{R}_{\mathrm{L}}, \mathrm{cmH}_{2} \mathrm{O} / \mathrm{L} / \mathrm{s}$ & $0.49 *$ & $0.60 * *$ & $-0.65^{* *}$ & $0.57^{*}$ & 0.06 & $-0.62 * *$ \\
\hline
\end{tabular}

Notes: $* P<0.05$ and $* * P<0.01$.

Abbreviations: OLD, obstructive lung disease; R5, respiratory resistance at $5 \mathrm{~Hz}$; R20, respiratory resistance at $20 \mathrm{~Hz}$; R5-R20, difference from R20 to R5; X5, respiratory reactance at $5 \mathrm{~Hz}$; fres, resonant frequency; $\triangle \mathrm{R} 5$ and $\Delta \mathrm{X} 5$, within-breath changes in R5 and X5; VC, vital capacity; FEV , forced expiratory volume in I second; FVC, forced vital capacity; DLCO, lung diffusion capacity of carbon monoxide; FRC, functional residual capacity; $\Delta \mathrm{N}_{2}$, N2 phase III slope of single-breath $\mathrm{N} 2$ washout; Cst, static compliance; $\mathrm{Cl}$, Cdyn during respiratory rate at I Hz; Cl/Cst, an index of frequency dependency; $\mathrm{R}_{\mathrm{L}}$, lung resistance. 


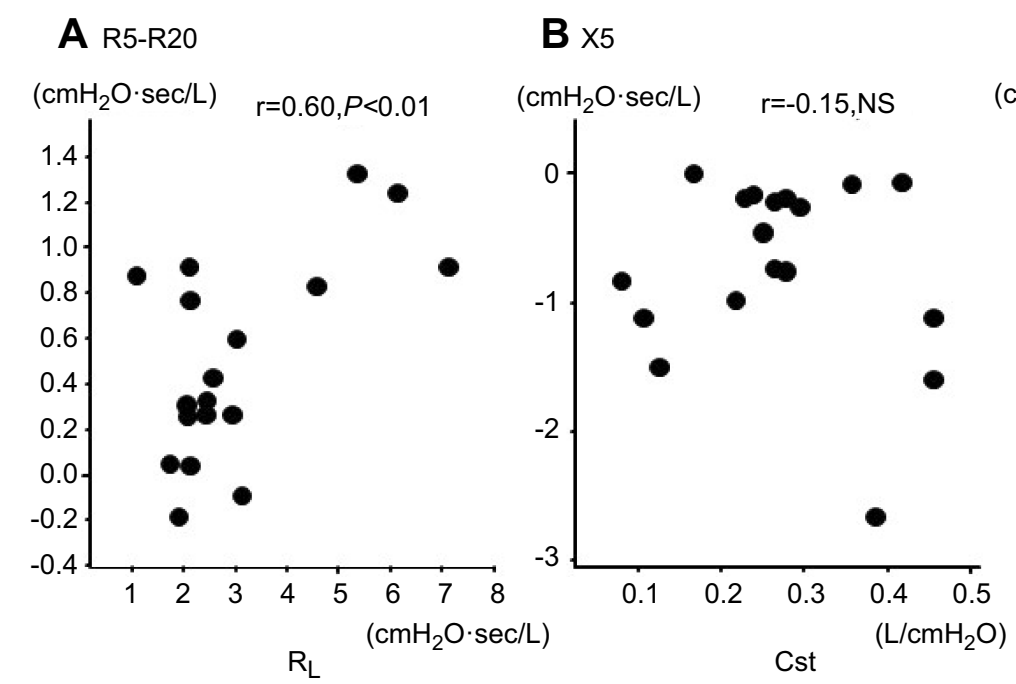

C $\times 5$

Cst

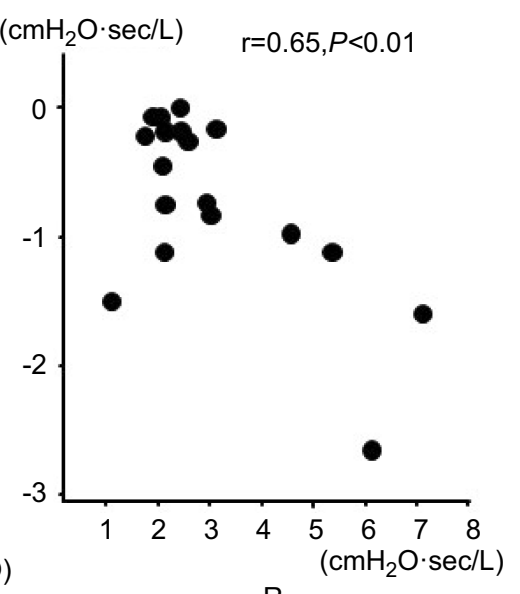

Figure 3 Relationships between lung resistance and R5-R20 (A) or X5 (C), and between static lung compliance and X5 (B) in obstructive lung disease. Hz. Abbreviations: R5, respiratory resistance at $5 \mathrm{~Hz}$; R20, respiratory resistance at $20 \mathrm{~Hz}$; R5-R20, difference from $R 20$ to $R 5 ; X 5$, respiratory reactance at $5 \mathrm{~Hz}$; $R_{L}$, lung resistance; Cst, static lung compliance.

Table 5 Correlations between parameters of respiratory impedance and pulmonary function tests in II patients with interstitial lung disease

\begin{tabular}{|c|c|c|c|c|c|c|}
\hline & $\mathbf{R 5}$ & R5-R20 & $\times 5$ & fres & $\Delta \mathbf{R 5}$ & $\Delta \times 5$ \\
\hline VC,\% & -0.19 & -0.29 & $0.6 I^{*}$ & $-0.66 * *$ & 0.10 & -0.10 \\
\hline$\% \mathrm{FEV}_{1}, \%$ & -0.40 & -0.48 & $0.69 *$ & $-0.78^{* *}$ & 0.06 & 0.00 \\
\hline $\mathrm{FEV}_{1} / \mathrm{FVC}, \%$ & -0.50 & -0.52 & 0.13 & -0.26 & -0.25 & 0.46 \\
\hline DLCO, \% & -0.09 & -0.20 & 0.38 & -0.38 & 0.29 & -0.27 \\
\hline FRC, \% & -0.04 & -0.18 & 0.06 & -0.24 & -0.10 & 0.20 \\
\hline$\Delta \mathrm{N}_{2}, \%$ & $0.64 *$ & $0.67^{*}$ & $-0.93 * *$ & $0.84 * *$ & 0.39 & -0.53 \\
\hline Cst, $\mathrm{L} / \mathrm{cmH}_{2} \mathrm{O}$ & -0.15 & -0.18 & 0.30 & -0.39 & 0.35 & -0.17 \\
\hline $\mathrm{Cl} / \mathrm{Cst}, \%$ & 0.14 & 0.13 & 0.14 & -0.00 & -0.16 & -0.05 \\
\hline $\mathrm{R}_{\mathrm{L}}, \mathrm{cmH}_{2} \mathrm{O} / \mathrm{L} / \mathrm{s}$ & 0.47 & 0.47 & $-0.77^{* *}$ & $0.7 I^{*}$ & 0.10 & -0.20 \\
\hline
\end{tabular}

Notes: $* P<0.05$ and $* * P<0.01$.

Abbreviations: ILD, interstitial lung disease; R5, respiratory resistance at $5 \mathrm{~Hz}$; R20, respiratory resistance at $20 \mathrm{~Hz}$; R5-R20, difference from R20 to R5; X5, respiratory reactance at $5 \mathrm{~Hz}$; fres, resonant frequency; $\Delta R 5$ and $\Delta X 5$, within-breath changes in R5 and X5; VC, vital capacity; FEV , forced expiratory volume in I second; FVC, forced vital capacity; DLCO, lung diffusion capacity of carbon monoxide; FRC, functional residual capacity; $\Delta \mathrm{N}_{2}$, N2 phase III slope of single-breath N2 washout; Cst, static compliance; $\mathrm{Cl}$, Cdyn during respiratory rate at $\mathrm{I} \mathrm{Hz} ; \mathrm{Cl} / \mathrm{Cst}$, an index of frequency dependency; $\mathrm{R}_{\mathrm{L}}$, lung resistance.

reactance and $\mathrm{FEV}_{1}$ were correlated with airway intraluminal area (Ai). Further, the percentage of low attenuation area of lung fields (\%LAA) was correlated with respiratory reactance, but the correlation coefficient was low $(r=-0.276)$. They suggested that emphysema shows a patchy distribution and causes heterogeneous airway collapse, which may be associated with respiratory reactance denoting ventilation unevenness. ${ }^{25,26}$ It was very interesting that the within-breath changes in X5 ( $\triangle \mathrm{X} 5$ ), which have been demonstrated to be associated with airway collapse in expiration, showed a tendency to be correlated with the respiratory frequency dependent decrease in Cdyn because it represents easy to cause air trapping.
In ILD, the low frequency-dependent increase in Rrs and more negative shift of Xrs were observed, as in OLD, and showed good correlations with ventilation unevenness, increased $\mathrm{R}_{\mathrm{L}}$, and volume loss, but not with Cst as well as in OLD. Lung compliance is decreased in ILD, while compliance is increased in emphysema. However, the changes in resistance and reactance at lower frequency in these two disease conditions were similar. The reason has not been resolved, however, three reasons may be considered. One reason is the presence of peripheral airway disease as well as in OLD. In the present study, 7 patients with ILD had smoking history and 2 had emphysema. The low-frequency dependent increase in resistance was significantly correlated with 


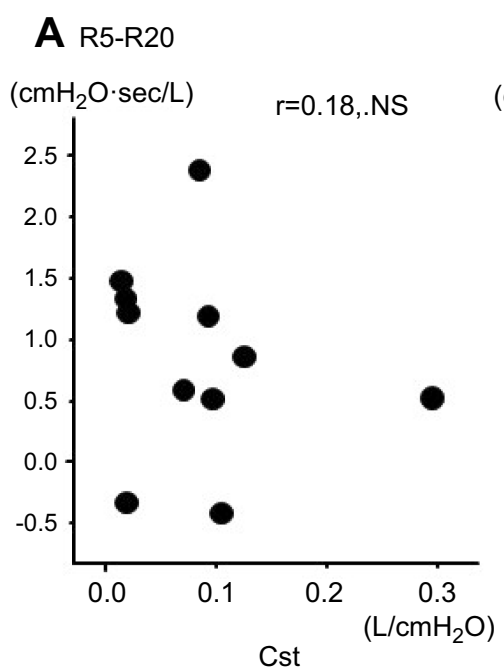

Cst
B $\times 5$

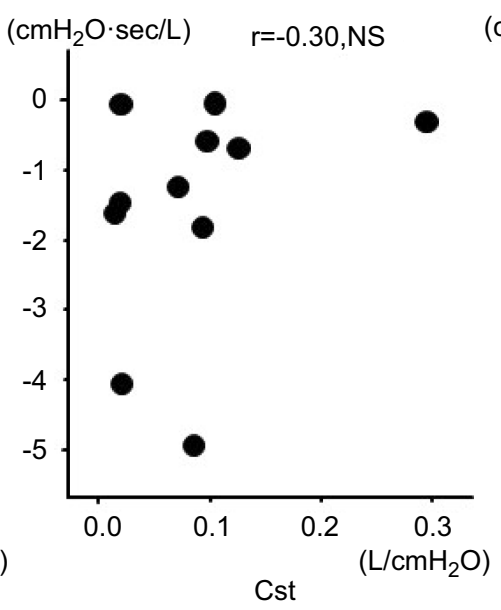

C $\times 5$

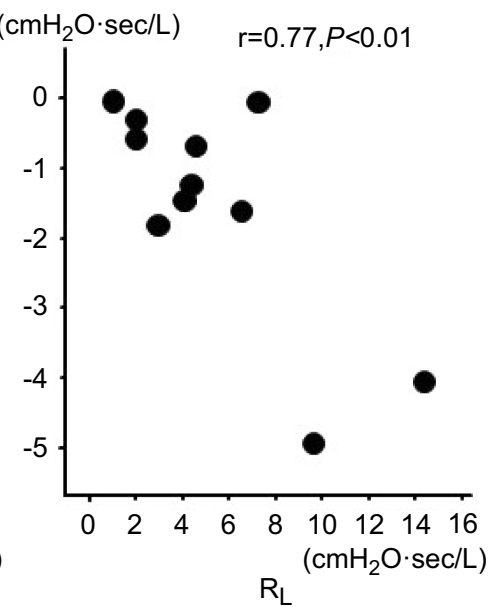

Figure 4 Relationships between static lung compliance and R5-R20 (A) or X5 (B), and between lung resistance and X5 (C) in interstitial lung disease. R5-R20: difference in resistance at oscillation of $5 \mathrm{~Hz}$ and $20 \mathrm{~Hz}$; X5, reactance at oscillation of $5 \mathrm{~Hz}$.

Abbreviations: R5, respiratory resistance at $5 \mathrm{~Hz}$; R20, respiratory resistance at $20 \mathrm{~Hz}$; R5 - R20, difference from R20 to R5; X5, respiratory reactance at $5 \mathrm{~Hz}$; Cst, static compliance; $R_{L}$, lung resistance.

ventilation unevenness and showed a tendency to correlate with airway obstruction. Most of patients with IPF have been demonstrated to be associated with smoking, and a large number of patients have emphysema and airway disease. ${ }^{27}$ Furthermore, some patients with interstitial pneumonia due to collagen disease also have airway disease. If the small airway lesion is present, the resistance is increased and more negative shift of reactance at low frequency, and the interstitial changes cannot be reflected. Mikamo et $\mathrm{al}^{28}$ reported that the 90 patients with ILD were divided into the two groups according to the presence or absence of small airway disease findings detected by HRCT, and the impedance parameters were compared. The absolute values of R5-R20, X5, and fres were elevated in ILD patients with small airway disease compared to those without small airway disease. Therefore, the FOT parameters are largely affected by the presence of small airway disease also in ILD. Moreover, it has been demonstrated that there were no significant differences in the indices of respiratory impedance between the airway lesion dominant and interstitial pneumonia dominant groups in patients with rheumatoid arthritis-related pulmonary abnormalities. ${ }^{29}$ This indicates the parenchymal abnormalities did not contribute to the changes in respiratory impedance in ILD. The second reason is the decrease of lung recruitment due to the compression or collapse airway and lung may resulted in the more negative shift of reactance from the fact that the decreased VC was significantly correlated with $\mathrm{X} 5$ and fres. In the third reason, it was suggested that airway stiffness due to peribronchial fibrosis in addition to interstitial fibrosis may occur, and the decreased airway compliance can contribute to the more negative shift of reactance.

This study had several limitations. The data were collected retrospectively from CLD and ILD patients, and the numbers of patients were small. In addition, the causes of OLD and ILD varied, especially in ILD, and the degree of airway pathological changes due to collagen disease or smoking may affect the impedance parameters. However, this was the first study to compare the respiratory impedance parameters and Cst or $\mathrm{R}_{\mathrm{L}}$ in not only OLD but also ILD, and may contribute to our understanding of the significance of FOT parameters.

\section{Conclusion}

In conclusion, the extent to which the decreased lung elastic recoil pressure due to emphysematous changes or pulmonary fibrosis contributes to the impedance parameters of FOT has not been determined. The present retrospective study indicated that the impedance parameters of FOT mainly reflected airway lesions, ventilation unevenness, and lung volume, but not changes in the lung parenchyma directly, not only in OLD but also possibly in ILD, because the oscillating pulse wave may be markedly affected by airways leading to alveoli.

\section{Summary at a glance}

Impedance parameters of forced oscillation technique mainly reflected airway lesions, ventilation unevenness, and lung volume, but not changes in lung parenchyma 
directly, not only in obstructive lung disease but also in interstitial lung disease, because the oscillating wave may be affected by airways leading to alveoli.

\section{Acknowledgment}

This work was not supported by any grant or other funding sources.

\section{Disclosure}

Prof. Dr. Keisaku Fujimoto reports grants from Koganei Corporation, Murata Manufacturing Co., LTD., Seiko Epson Corporation, Denso Corporation, grants and personal fees from Nippon Boehringer Ingelheim Co., Ltd., personal fees from Astellas Pharma Inc., AstraZeneca K.K., Fukuda Denshi Co., Ltd, Fukuda Lifetec Co., Ltd., Japan Association for the Advancement of Medical Equioment, Japan Respiratory Society, Kyorin Pharmaceutical Co., Ltd, Meiji Seika Pharma Co., Ltd., MSD K.K., Novartis Pharma K.K., Teijin Home Healthcare Limited, and Teijin Pharma Limited, outside the submitted work. The authors report no other conflicts of interest in this work.

\section{References}

1. Oostveen E, Macleod D, Lorino H, et al. The forced oscillation technique in clinical practice: methodology, recommendations and future developments. Eur Respir J. 2003;22:1026-1041.

2. Bickel S, Popler J, Lesnick B, Eid N. Impulse oscillometry: interpretation and practical applications. Chest. 2014;146:841-847. doi:10.1378/chest.13-1875

3. Shirai T, Kurosawa H. Clinical application of the forced oscillation technique. Intern Med. 2016;55:559-566. doi:10.2169/ internalmedicine. 55.5876

4. Mori K, Shirai T, Mikamo M, et al. Colored 3-dimensional analyses of respiratory resistance and reactance in COPD and asthma. Copd. 2011;8:456-463. doi:10.3109/15412555.2011.626818

5. Cavalcanti JV, Lopes AJ, Jansen JM, Melo PL. Detection of changes in respiratory mechanics due to increasing degrees of airway obstruction in asthma by the forced oscillation technique. Respir Med. 2006;100(12):2207-2219. doi:10.1016/j.rmed.2006.03.043

6. Paredi P, Goldman M, Alamen A, et al. Comparison of inspiratory and expiratory resistance and reactance in patients with asthma and chronic obstructive pulmonary disease. Thorax. 2010;65:263-267. doi:10.1136/thx.2009.120790

7. Kanda S, Fujimoto K, Komatsu Y, Yasuo M, Hanaoka M, Kubo K. Evaluation of respiratory impedance in asthma and COPD by an impulse oscillation system. Intern Med. 2010;49(1):23-30. doi:10.2169/internalmedicine.49.2191

8. Dellaca RL, Santus P, Aliverti A, et al. Detection of expiratory flow limitation in COPD using the forced oscillation technique. Eur Respir J. 2004;23(2):232-240. doi:10.1183/09031936.04.00046804

9. Van Noord JA, Clément J, Cauberghs M, Mertens I, Van de Woestijne KP, Demedts M. Total respiratory resistance and reactance in patients with diffuse interstitial lung disease. Eur Respir J. 1989;2(9):846-852.

10. Sugiyama A, Hattori N, Haruta Y, et al. Characteristics of interstitial and expiratory reactance in interstitial lung disease. Respir Med. 2013;107:875-882. doi:10.1016/j.rmed.2013.03.005
11. Wada Y, Kitaguchi Y, Yasuo M, et al. Diversity of respiratory impedance based on quantitative computed tomography in patients with COPD. Int J Chron Obstruct Pulmon Dis. 2018;13:1841-1849. doi:10.2147/COPD.S163129

12. Goldman MD, Saadeh C, Ross D. Clinical applications of forced oscillation to assess peripheral airway function. Respir Physiol Neuro. 2005;148:179-194. doi:10.1016/j.resp.2005.05.026

13. Venegas JG, Harris RS, Simon BA. A comprehensive equation for the pulmonary pressure-volume curve. $J$ Appl Physiol. 1998;84:389-395. doi:10.1152/jappl.1998.84.1.389

14. Ingenito EP, Evans RB, Loring SH, et al. Relation between preoperative inspiratory lung resistance and the outcome of lung-volumereduction surgery for emphysema. $N$ Engl $J$ Med. 1998;338:1181-1185. doi:10.1056/NEJM199804233381703

15. Mase K, Yamamoto K, Murakami S, et al. Changes in ventilation mechanics during expiratory rib cage compression in healthy males. J Phys Ther Sci. 2018;30:820-824. doi:10.1589/jpts.30.820

16. Hida W, Suzuki S, Sasaki H, Fujii Y, Sasaki T, Takishima T. Effect of ventilatory frequency on regional transpulmonary pressure in normal adults. J Appl Physiol. 1981;51:678-685. doi:10.1152/ jappl.1981.51.3.678

17. Sasaki E, Nakamura M, Kida K, et al. Reference values for spirogram and blood gas analysis in Japanese adults. J Jpn Respir Soc. 2001;39 (5):S1-S17.

18. Nishida O, Kambe M, Sewake N, Takano M, Kawane H. Pulmonary function in healthy subjects and its prediction: 5 . Pulmonary diffusing capacity in adults. Jpn J Clin Pathol. 1976;24:941-947.

19. Boren HG, Kory RC, Syner JC. The veterans administration-army cooperative study of pulmonary function. $A m \quad J \quad M e d$. 1966;41:96-114. doi:10.1016/0002-9343(66)90008-8

20. Milne S, Hammans C, Watson S, Farah CS, Thamrin C, King GG. Bronchodilator responses in respiratory impedance, hyperinflation and gas trapping in COPD. $J$ Chron Obstruct Pulmon Dis. 2018;15:341-349. doi:10.1080/15412555.2018.1458217

21. Lutchen KR, Gillis H. Relationship between heterogeneous changes in airway morphometry and lung resistance and elastance. $J$ Appl Physiol. 1997;83:1192-1201. doi:10.1152/jappl.1997.83.4.1192

22. Dellaca RL, Andersson Olerud M, Zannin E, et al. Lung recruitment assessed by total respiratory system input reactance. Intensive Care Med. 2009;35:2164-2172. doi:10.1007/s00134-009-1673-3

23. Nilsen K, Thien F, Thamrin C, et al. Early onset of airway de-recruitment assessed using the forced oscillation technique in subjects with asthma. J Appl Physiol. 2019. doi:10.1152/ japplphysiol.00534.2018

24. Karayama M, Inui N, Mori K, et al. Respiratory impedance is correlated with morphological changes in the lungs on three-dimensional $\mathrm{CT}$ in patients with COPD. Sci Rep. 2017;7:41709. doi:10.1038/srep41

25. Mikamo M, Shirai T, Mori K, et al. Predictors of expiratory flow limitation measured by forced oscillation technique in COPD. BMC Pulm Med. 2014;14:23. doi:10.1186/1471-2466-14-23

26. Bhatawadekar SA, Leary D, Maksym GN. Modelling resistance and reactance with heterogeneous airway narrowing in mild to severe asthma. Can J Physiol Pharmacol. 2015;93:207-214. doi:10.1139/ cjpp-2014-0436

27. Kumar A, Cherian SV, Vassallo R, Yi ES, Ryu JH. Current concepts in pathogenesis, diagnosis, and management of smoking-related interstitial lung diseases. Chest. 2018;154:394-408. doi:10.1016/j. chest.2017.11.023

28. Mikamo M, Fujisawa T, Oyama Y, et al. Clinical significance of forced oscillation technique for evaluation of small airway disease in interstitial lung diseases. Lung. 2016;194:975-983. doi:10.1007/ s00408-016-9949-1

29. Sokai R, Ito S, Iwano $S$, et al. Respiratory mechanics measured by forced oscillation technique in rheumatoid arthritis-related pulmonary abnormalities: frequency-dependence, heterogeneity and effects of smoking. SpringerPlus. 2016;5:335. doi:10.1186/s40064-016-1952-8 


\section{Publish your work in this journal}

The International Journal of COPD is an international, peer-reviewed journal of therapeutics and pharmacology focusing on concise rapid reporting of clinical studies and reviews in COPD. Special focus is given to the pathophysiological processes underlying the disease, intervention programs, patient focused education, and self management protocols. This journal is indexed on PubMed Central, MedLine and CAS. The manuscript management system is completely online and includes a very quick and fair peer-review system, which is all easy to use. Visit http://www.dovepress.com/testimonials.php to read real quotes from published authors.

Submit your manuscript here: https://www.dovepress.com/international-journal-of-chronic-obstructive-pulmonary-disease-journal 